\title{
Erosion of Composite Resins
}

\author{
J. M. POWERS and P. L. FAN
}

School of Dentistry, The University of Michigan, Ann Arbor, Michigan 48109

The surface degradation of composite resins caused by accelerated aging was studied. Accelerated aging for 900 hours caused erosion of the resin matrices and exposure of filler particles. Differences in surface profiles after aging suggest that the materials eroded at different rates. Accelerated aging may model erosive wear of compos. ites.

\section{J Dent Res 59(5):815-819, May 1980}

\section{Introduction.}

The wear of posterior composite restorations has been described by Kusy and Leinfelder ${ }^{1}$ as a process where exfoliation of the inorganic filler particles occurs as the resin matrix is continually worn away. O'Brien and $\mathrm{Yee}^{2}$ have reported crazing of the polymer matrix on the occlusal surfaces of several clinical restorations. They suggested that the loss of irregularly shaped inorganic filler particles occurs through the cohesive failure of the matrix rather than interfacial failure. The purpose of this investigation is to describe the surface degradation of restorative resins caused by accelerated aging conditions.

\section{Materials and methods.}

Seven commercial composite resins and an acrylic restorative resin were tested. Codes, shades, batch numbers, and manufacturers of the materials are listed in Table 1.

Received for publication May 14, 1979

Accepted for publication August 1, 1979 This investigation was supported in whole by U.S.P.H.S. Research Grant DE-03416 from the National Institute of Dental Research, National Institutes of Health, Bethesda, MD 20205.

This investigation was presented at the annual meeting of the International Association for Dental Research in New Orleans, LA in March, 1979.

The cooperation of the following companies in providing commercial products is acknowledged: L. D. Caulk Co., Johnson \& Johnson, Kerr Manufacturing Co., Lee Pharmaceuticals, and $3 \mathrm{M}$ Co.
Eight disks $(36 \mathrm{~mm}$ in diameter and $\mathbf{1 . 3}$ $\mathrm{mm}$ in thickness) were made for each product by polymerizing five specimens in a rough metal die and three specimens in a smooth plastic die. The specimens were placed in an oven at $37^{\circ} \mathrm{C}$ within 90 seconds after initiating the mix and were stored for 24 hours before making the baseline evaluation. Specimens of the composite resin activated by ultraviolet light $(\mathrm{N})$ were polymerized by exposing one side of the sample to an ultraviolet light source* for two minutes at a distance of $5 \mathrm{~cm}$.

The disks were exposed to conditions of accelerated aging for a total of 900 hours in a weathering chamber ${ }^{+}$at $43^{\circ} \mathrm{C}$ and 90 percent relative humidity. One surface of each sample was subjected continuously to the radiation of a 2500-watt xenon light source $^{\ddagger}$ filtered by borosilicate glass and to an intermittent water spray for 18 minutes every two hours. Evaluations of color and roughness were made before weathering (baseline) and after exposures of 300,600 , and 900 hours.

Data for percent reflectance versus wavelength $(\lambda)$ were obtained for the samples between 405 and $700 \mathrm{~nm}$ with a doublebeam, ultraviolet-visible spectrophotometer $\S$ and integrating sphere. The output data of the spectrophotometer were recorded $(\Delta \lambda=$ $5 \mathrm{~nm}$ ) on punched paper tape through a digital intercoupler. 1 Luminous reflectance (Y), dominant wavelength (DW), and excitation purity (EP) were obtained for each

*Blak-Ray, Model B-100A, Ultra-Violet Products, Inc., San Gabriel, CA 91775

+Weather-Ometer, 25-WR, Atlas Electric Devices, Inc., Chicago, IL 60613

₹12-2881 Xenon Burner, Atlas Electric Devices, Inc., Chicago, IL 60613

$\S$ ACTA CIII UV-visible Spectrophotometer, Beckman Instruments, Inc., Irvine, CA 92664

\#ASPH-U Integrating Sphere, Beckman Instruments, Inc., Irvine, CA 92664

Auto-Pro 31098 Intercoupler, Beckman Instruments, Inc., Irvine, CA 92664 
TABLE 1

CODE, PRODUCT, BATCH NUMBER, AND MANUFACTURER OF PRODUCTS TESTED

\begin{tabular}{|c|c|c|c|}
\hline Code & $\begin{array}{l}\text { Product Name } \\
\quad \text { (Shade) }\end{array}$ & Batch Numbers & Manufacturers \\
\hline $\begin{array}{l}\text { Composites: } \\
\text { A }\end{array}$ & $\begin{array}{l}\text { Adaptic } \\
\text { (Universal) }\end{array}$ & $\begin{array}{l}\text { base - SF } 101,8 \mathrm{C} 004 \\
\text { catalyst - SF 101, 8C004 }\end{array}$ & $\begin{array}{l}\text { Johnson \& Johnson } \\
\text { Dental Products Division } \\
\text { East Windsor, NJ } 08520\end{array}$ \\
\hline RA & Adaptic Radiopaque & base $-1126 \mathrm{D} 03,8 \mathrm{H} 109$ & Johnson \& Johnson \\
\hline $\mathrm{C}$ & $\begin{array}{l}\text { Concise } \\
\text { (Universal) }\end{array}$ & $\begin{array}{l}\text { base }-6159 \mathrm{~L} 13,8 \mathrm{Y} 21 \\
\text { catalyst }-6159 \mathrm{~L} 13,8 \mathrm{Y} 21\end{array}$ & $\begin{array}{l}\text { 3 M Company } \\
\text { St. Paul, MN } 55101\end{array}$ \\
\hline $\mathrm{N}$ & $\begin{array}{l}\text { Nuva-Fil } \\
\text { (Light, Light Green) }\end{array}$ & $\begin{array}{l}\text { base }-7426,73299 \\
\text { initiator }-7661\end{array}$ & $\begin{array}{l}\text { L. D. Caulk Company } \\
\text { Div. of Dentsply Interna- } \\
\text { tional, Inc. } \\
\text { Milford, DE } 19963\end{array}$ \\
\hline$P$ & $\begin{array}{l}\text { Prestige } \\
\text { (Universal) }\end{array}$ & $\begin{array}{l}\text { base - HPR0114 } \\
\text { catalyst - HPRO115 }\end{array}$ & $\begin{array}{l}\text { Lee Pharmaceuticals } \\
\text { South El Monte, CA } 91733\end{array}$ \\
\hline $\mathrm{S}$ & $\begin{array}{l}\text { Simulate } \\
\text { (Universal) }\end{array}$ & $\begin{array}{l}\text { base }-1066,772216 \\
\text { catalyst }-1160,771231\end{array}$ & $\begin{array}{l}\text { Kerr Manufacturing Co, } \\
\text { Div. of Sybron Corporation } \\
\text { Romulus, MI } 48174\end{array}$ \\
\hline $\mathrm{v}$ & $\begin{array}{l}\text { Vytol } \\
\text { (Light) }\end{array}$ & $\begin{array}{l}\text { base }-042976,041278 \\
\text { catalyst }-042976,041478\end{array}$ & L. D. Caulk Company \\
\hline $\begin{array}{l}\text { Acrylic Resin: } \\
\text { SV }\end{array}$ & $\begin{array}{l}\text { Sevriton } \\
\text { (SS - Light Yellow) }\end{array}$ & $\begin{array}{l}\text { powder - PA14PE, RF15 } \\
\text { liquid - PH6PK, BNUK13UL }\end{array}$ & $\begin{array}{l}\text { Amalgamated Dental Trade } \\
\text { Dist., Ltd. } \\
\text { London, England }\end{array}$ \\
\hline
\end{tabular}

TABLE 2

RATIOS OF COLOR PARAMETERS $\left(\mathrm{X}_{\text {back }} / \mathrm{X}_{\text {front }}\right)$ FOR COMPOSITE RESIN S DURING AGING

\begin{tabular}{cccccc}
\hline & & \multicolumn{4}{c}{$\mathrm{X}_{\text {back }} / \mathrm{X}_{\text {front }}$ versus Aging - Smooth Die } \\
\cline { 3 - 6 } Code & Parameter, $\mathrm{X}$ & \multicolumn{4}{c}{ Time of Exposure, Hrs } \\
\cline { 3 - 6 } & & 0 & 300 & 600 & 900 \\
\hline S & EP & $0.99(0.02)$ & $0.91(0.02)$ & $0.90(0.01)$ & $1.36(0.22)$ \\
& Y & $1.00(0.01)$ & $1.01(0.01)$ & $1.00(0.01)$ & $1.00(0.01)$ \\
& DW & $1.00(0.01)$ & $1.00(0.01)$ & $1.00(0.01)$ & $1.00(0.01)$ \\
& CR & $1.01(0.01)$ & $1.01(0.01)$ & $1.00(0.01)$ & $0.98(0.01)$ \\
& & & & &
\end{tabular}

sample backed by both a black** and a white $^{++}$standard. ${ }^{3}$ An estimate of the opacity of each sample was obtained by calculation of the contrast ratio $(C R),{ }^{4}$ $\mathrm{Y}_{\text {black standard }} / \mathrm{Y}_{\text {white standard. }}$. Both the side of the sample exposed to the xenon light (front side) and the unexposed side (back side) were evaluated for change in color, and a ratio of $\mathrm{X}_{\text {back }} / \mathrm{X}_{\text {front }}$ was calculated for each parameter of color.

**Part No. 375287, Beckman Instruments, Inc., Irvine, CA 92664

${ }^{++}$Part No. 104384, Beckman Instruments, Inc., Irvine, CA 92664
Surface roughness of the exposed and unexposed surfaces of each sample was measured from profile tracings. arithmetic average roughness was determined. Surface degradation also was observed using a scanning electron microscope. $\S \S$

The data were analyzed by analysis of variance, 5 and mean values were compared by Scheffe intervals. 6

$\$ \ddagger$ Surfanalyzer 150 , Gould, Inc., Instrument Systems Division, Cleveland, OH 44114

$\S \S$ SMS-II International Scientific Instruments, Mountain View, CA 94043 


\section{Results.}

The ratio of parameter of color $\left(\mathrm{X}_{\mathrm{back}}\right)$ $X_{\text {front }}$ ) that showed the greatest change during aging was the ratio for excitation purity, as shown in Table 2, for composite resin $\mathrm{S}$ made in the smooth die. Between 0 and 600 hours, the side of the sample exposed to the xenon light became more chromatic than the unexposed side. Between 600 and 900 hours, the excitation purity of the exposed side of $\mathrm{S}$ became much less chromatic than the unexposed side.

The ratios of excitation purity after 900 hours of aging for the samples prepared in the rough and the smooth dies are listed in Table 3. The largest values of this ratio were observed for the composites $\mathrm{P}, \mathrm{S}$, and $\mathrm{V}$ and for the acrylic resin SV. The ratios determined for the samples made in the rough die were larger than the ratios of the samples made in the smooth die. With a few exceptions, the ratios were greater than 1.00 , indicating that the exposed sides of the resins were less chromatic than the unexposed sides.

The average roughness of the front and back sides of $S$ as a function of aging is shown in Table 4. Between 0 and 600 hours, the changes in average roughness of both surfaces were small. After 900 hours of aging, however, the average roughness of the

TABLE 3

RATIO OF EXCITATION PURITY (back/front) FOR MATERIALS AFTER AGING

\begin{tabular}{llc} 
& \multicolumn{2}{c}{$\mathrm{EP}_{\text {back }} / \mathrm{EP}_{\text {front }}$ at 900 Hours } \\
\cline { 2 - 3 } Code & Rough Die & Smooth Die \\
\hline $\mathrm{A}$ & $1.21(0.09)^{*}$ & $1.06(0.06)^{+}$ \\
$\mathrm{C}$ & $1.24(0.10)$ & $1.10(0.10)$ \\
$\mathrm{N}$ & $1.25(0.05)$ & $0.96(0.02)$ \\
$\mathrm{P}$ & $3.43(0.35)$ & - \\
RA & $1.33(0.11)$ & $0.94(0.06)$ \\
S & $1.43(0.12)$ & $1.36(0.22)$ \\
V & $1.60(0.06)$ & $1.16(0.12)$ \\
SV & $1.41(0.14)$ & $1.28(0.08)$ \\
\hline
\end{tabular}

* Mean of 5 replications with standard deviations in parentheses. Scheffe interval is 0.24 at the 95 percent level of confidence (excluding P).

${ }^{+}$Mean of 3 replications with standard deviations in parentheses. Scheffe interval is 0.26 at the 95 percent level of confidence (excluding $S$ ). exposed surface was much greater than that of the unexposed surface or the exposed surface at 600 hours.

Values of average roughness ( $R$ ) of the exposed sides of the samples prepared in the rough and smooth dies are shown in Table 5 after 900 hours of aging. The changes in average roughness $(\Delta R)$ between 0 and 900 hours are also listed. For samples made in the rough die, changes in roughness and profile were observed, as illustrated in Fig. 1 for $C$ and $S$. After aging for 900 hours, the exposed surfaces of the samples became rougher because of exposure of the filler particles. For $P, S, V$, and $S V$, the profile decreased enough to lower the average surface roughness. For $\mathrm{A}, \mathrm{C}, \mathrm{N}$, and RA, the average surface roughness increased, suggesting there was little change in the profile. The samples made in the smooth die all became rougher after 900 hours of aging, except $\mathrm{N}$ and $\mathrm{SV}$. The average roughness of $\mathrm{N}$ did not change during aging, whereas that of SV decreased from its initial value which was considerably greater than that of the composites.

Scanning electron photomicrographs of the surfaces of $A, N, P$, and SV made in the rough die are shown in Fig. 2 after aging for 900 hours. The surfaces of A, C, and RA were similar, as well as those of $P, S$, and $V$. However, the surfaces of $\mathrm{N}$ and SV were

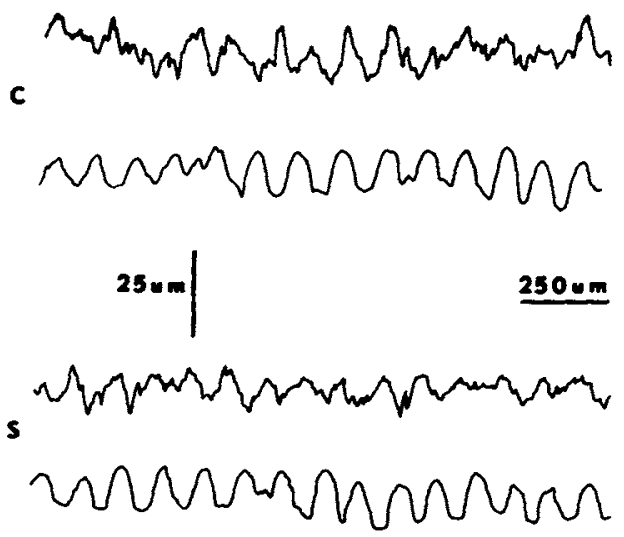

Fig. 1 - Profiles of surface roughness for composites $C$ and $S$ made in a rough die. In each, the lower and upper curves refer to 0 and 900 hours of aging, respectively. 

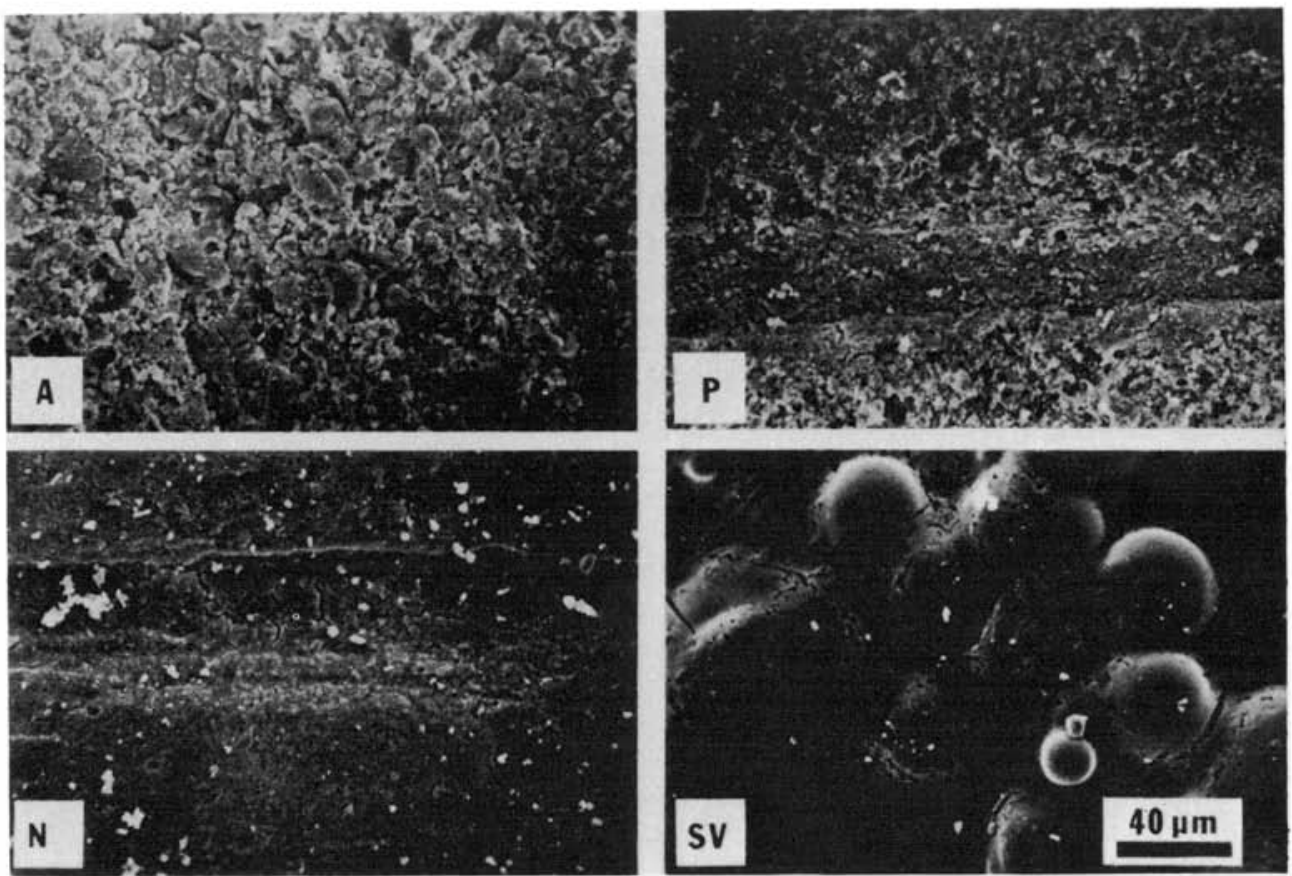

Fig. 2 - Scanning electron photomicrographs of exposed surfaces of composites (A, P, and N) and acrylic resin (SV) made in a rough die and aged for 900 hours.

TABLE 4

ROUGHNESS VERSUS AGING OF COMPOSITE RESIN S MADE IN THE SMOOTH DIE

\begin{tabular}{lcccr}
\hline \hline & \multicolumn{4}{c}{ Roughness, $\mu \mathrm{m}$} \\
\cline { 2 - 5 } Code & 0 & 300 & 600 & 900 \\
\cline { 2 - 5 } & $0.02(0.00)^{*}$ & $0.05(0.01)$ & $0.06(0.02)$ & $0.31(0.10)$ \\
Front & $0.02(0.00)$ & $0.05(0.02)$ & $0.04(0.01)$ & $0.04(0.01)$ \\
Back & & & & \\
\end{tabular}

* Mean of 3 replications with standard deviations in parentheses.

different from those of the other materials, and surface crazing was observed for the latter.

\section{Discussion.}

Accelerated aging for 900 hours caused surface degradation of the materials tested. Erosion of the composite matrices and exposure of filler particles were observed. The erosion process seemed to occur at different rates for the various materials as evidenced by the changes in the surface profiles of $\mathrm{P}, \mathrm{S}, \mathrm{V}$, and $\mathrm{SV}$ when compared to A, C, N, and RA. Measurements of volume loss on samples of a more appropriate size than those in this study would help confirm the different rates of erosion.

Studies of in vivo composite restorations have also reported surface crazing and exposure of filler particles. ${ }^{1,2}$ In the present study, these phenomena probably were accelerated by the radiation of the xenon lamp. Such radiation may cause a freeradical degradation of the composite resin matrix in vitro which is accelerated by a 
TABLE 5

ROUGHNESS OF COMPOSITE RESINS AFTER 900 HOURS OF AGING

\begin{tabular}{|c|c|c|c|c|}
\hline \multirow[b]{3}{*}{ Code } & \multicolumn{4}{|c|}{ Roughness (R), $\mu \mathrm{m}$} \\
\hline & \multicolumn{2}{|c|}{ Rough Die } & \multicolumn{2}{|c|}{ Smooth Die } \\
\hline & $900 \mathrm{Hrs}$ & $\Delta \mathrm{R}, 900 \mathrm{Hr}-0 \mathrm{Hr}$ & $900 \mathrm{Hrs}$ & $\Delta \mathrm{R}, 900 \mathrm{Hr}-0 \mathrm{Hr}$ \\
\hline A & $2.33(0.20)^{*}$ & 0.08 & $0.25(0.09)^{+}$ & 0.19 \\
\hline $\mathrm{C}$ & $2.60(0.13)$ & 0.35 & $0.21(0.05)$ & 0.17 \\
\hline $\mathrm{N}$ & $2.35(0.66)$ & 0.10 & $0.02(0.01)$ & 0.00 \\
\hline $\mathbf{P}$ & $1.67(0.48)$ & -0.58 & -- & -- \\
\hline RA & $2.40(0.14)$ & 0.15 & $0.17(0.02)$ & 0.13 \\
\hline $\mathrm{S}$ & $1.67(0.12)$ & -0.58 & $0.31(0.10)$ & 0.26 \\
\hline V & $1.73(0.10)$ & -0.52 & $0.15(0.02)$ & 0.11 \\
\hline SV & $2.02(0.08)$ & -0.23 & $0.13(0.10)$ & -0.30 \\
\hline
\end{tabular}

*Mean of six replications with standard deviations in parentheses. Scheffe interval is $0.27 \mu \mathrm{m}$ at the 95 percent level of confidence (excluding data of $\mathrm{N}$ and $\mathrm{P}$ ).

${ }^{+}$Mean of three replications with standard deviations in parentheses. Scheffe interval is $0.22 \mu \mathrm{m}$ at the 95 percent level of confidence.

source other than ultra-violet radiation in vivo. The relative importance of the water spray and the xenon radiation on the surface degradation in vitro remains to be determined. The effect of accelerated aging of composites on their resistance to mechanical forms of wear, such as abrasion and singlepass sliding, must also be evaluated.

\section{Conclusions.}

Conditions of accelerated aging for 900 hours caused erosion of the matrices and exposure of filler particles of the composite resins tested. The surface degradation was evaluated by changes in excitation purity and roughness. Differences in surface profiles after aging suggested that the materials eroded at different rates. It may be that accelerated aging could be used as a model to simulate the erosive wear of composite resins.

\section{REFERENCES}

1. KUSY, R.P. and LEINFELDER, K.F.: Pattern of Wear in Posterior Composite Restorations, $J$ Dent Res 56:544, 1977.

2. O'BRIEN, W. J. and YEE, J., Jr.: Surface Structure of Class II Composite Restorations After Clinical Wear, AADR Progr \& Abst $53: 327,1979$.

3. DENNISON, J.B.; POWERS, J.M.; and KORAN, A.: Color of Dental Restorative Resins, $J$ Dent Res 57:557-62, 1978.

4. Opacity of Paper, D589-65 (1970). (In ASTM Standards, part 20, 1975.) Philadelphia, PA: American Society for Testing and Materials, 1975, pp. 86-88.

5. A Manual of Elementary Statistics Using MIDAS, Ann Arbor: Statistical Research Laboratory, University of Michigan, 1975, p. 301.

6. GUENTHER, W.C.: Analysis of Variance. Englewood Cliffs, NJ: Prentice-Hall, Inc., 1964, p. 141. 